\title{
Conflicts of Interest and Outcomes of Cardiovascular Trials
}

\author{
Haris Riaz, MD ${ }^{\mathrm{a}, *}$, Muhammad Shahzeb Khan, MD ${ }^{\mathrm{b}}$, Irbaz Bin Riaz, MD ${ }^{\mathrm{c}}$, Sajjad Raza, MD , \\ Abdur Rahman Khan, MD ${ }^{\mathrm{e}}$, and Richard A. Krasuski, MD ${ }^{\mathrm{f}}$
}

\begin{abstract}
Conflicts of interests have long been recognized as potential sources of influence in the conduct and reporting of clinical trials. This controversy was again rekindled after the publication of the latest statin guidelines and a series of studies regarding competing interests in leading medical journals. We investigate the association between declared author conflicts and the outcomes of large cardiovascular trials. We searched the Medline (PubMed) database to identify "phase 2" and "phase 3" clinical trials using the search term "cardiovascular" over the past decade using "10 years" as the filter. We perceived the competing interest as present regardless of the nature such as consulting fees, honoraria, travel imbursements, stock holding, and employment. Of the 699 titles retrieved, 114 studies met the inclusion criteria. Nearly $80 \%$ of studies had at least a single author with competing interests. The 114 studies had a total of 1,433 investigators, of which 725 had declared conflicts of interests $(50.6 \%)$. A total of 66 studies $(58 \%)$ had half or $>50$ percent of investigators who had some conflicts of interests. Of these studies, 54 studies had favorable outcomes and only 12 had unfavorable outcomes $(p<0.001)$. Among the type of competing interests, consulting or personal fees was the most common present in 58 investigators $(51 \%)$. This was followed by research grants present in 55 the researchers $(48 \%)$. Among 25 (22\%) studies, at least one investigator reported stakes in the industry, of which only 2 studies had unfavorable outcomes for the intervention being investigated. Just 1 of the 25 clinical trials with a sample size of $>1,000$ had no investigators with competing interests. In conclusion, authors conflicts are associated with favorable outcomes in cardiovascular outcome trials. (c) 2016 Elsevier Inc. All rights reserved. (Am J Cardiol 2016;117:858-860)
\end{abstract}

Cardiovascular disease continues to be the leading cause of mortality across the globe and therefore an unbiased dissemination of cardiovascular research data is critical to ensure the highest ethical standards, which may be compromised by existing competing interests among the researchers. The issue of the competing interests among the investigators was again highlighted by the latest statin guidelines and a series of studies in leading medical journals. Recently, we demonstrated that financial interests are associated with outcomes that are favorable to the industry and this relation holds true even in a prepublication database suggesting that the publication bias alone cannot account for such findings. ${ }^{1}$ The current trends in the frequency of competing interests among the leading cardiovascular researchers are unknown. Herein, we investigate the association between declared author conflicts and the outcomes of large cardiovascular trials.

\footnotetext{
${ }^{\mathrm{a}}$ Department of Internal Medicine and ${ }^{\mathrm{d}}$ Department of Cardiac Surgery, Heart and Vascular Institute, Cleveland Clinic, Ohio; 'bepartment of Internal Medicine, Dow University of Health Sciences, Karachi, Pakistan; ${ }^{\mathrm{c}}$ Department of Internal Medicine, University of Arizona, Tucson, Arizona; ${ }^{\mathrm{e}}$ Department of Cardiovascular Medicine, University of Louisville, Louisville, Kentucky; and ${ }^{\mathrm{f}}$ Department of Cardiovascular Medicine, Duke University, North Carolina. Manuscript received October 3, 2015; revised manuscript received and accepted December 1, 2015.

See page 859 for disclosure information.

*Corresponding author: Tel/fax: $(+1) 2166447103$.

E-mail address: riazh@ccf.org (H. Riaz).
}

\section{Methods}

We searched the Medline (PubMed) database to identify "phase 2" and "phase 3" clinical trials using the search term "cardiovascular" over the past decade using "10 years" as the filter. This generated 699 titles, from which only randomized controlled trials were selected. Subgroup analyses, interim analyses, and publications of study designs were excluded. The last date of the report search was end of July 2015. Two investigators performed the report search independently. A mutually agreed template was used for the extraction of data. We perceived the competing interest as present regardless of the nature such as consulting fees, honoraria, travel imbursements, stock holding, and employment. Results of the studies were labeled "favorable" if the results favored the intervention under investigation, or "unfavorable" if the intervention fared worse or similar to standard medical treatment. We examined the studies regardless of the funding sources, whether industry, federally (such as National Institute of Health) or independently sponsored. For the purpose of statistical analysis, the studies were categorized into 2 groups, based on whether the investigators reported financial interests or not, and the data were analyzed through the statistical package of social sciences (SPSS version 17.0). The 2 groups were compared for differences in outcomes using Fischer's exact test. Results were expressed as 95\% CIs and deemed significant if the $\mathrm{p}$ value $<0.05$.

\section{Results}

Using the search strategy described in the methods, a total of 699 titles were identified and 114 studies met 
Table 1

Shows number of studies with unfavorable outcomes in regard to number of investigators with competing interests

\begin{tabular}{lccc}
\hline $\begin{array}{l}\text { \# Authors with } \\
\text { Competing Interests }\end{array}$ & \# Studies & $\begin{array}{c}\text { \# Studies with } \\
\text { Unfavorable Outcomes }\end{array}$ & $\begin{array}{c}\% \text { Unfavorable } \\
\text { Outcomes }\end{array}$ \\
\hline 0 & 23 & 15 & $65 \%$ \\
$1-4$ & 21 & 5 & $24 \%$ \\
$\geq 5$ & 70 & 15 & $21 \%$ \\
\hline
\end{tabular}

inclusion criteria after full review. The reasons for exclusions of most studies were being noncardiovascular or study types other than the phase 2 and 3 clinical trials. Most of these studies $(69 \%)$ were sponsored by industry and were from the United States $(51 \%)$. Nearly $80 \%$ of all studies had at least a single investigator with competing interests. The 114 studies had a total of 1,433 investigators, of which 725 had declared conflicts of interests (50.6\%). A total of 66 studies $(58 \%)$ had half or $>50$ percent of investigators who had some conflicts of interests. Among these studies, 54 studies had favorable outcomes and only 12 had unfavorable outcomes $(\mathrm{p}<0.001)$. Among the type of competing interests, consulting or personal fees was the most common present in 58 investigators (51\%). This was followed by research grants, present in 55 the researchers (48\%). Among $25(22 \%)$ studies, at least one investigator reported stakes in the industry, of which only 2 studies had unfavorable outcomes for the intervention being investigated. Five or more investigators with competing interests were present in $61 \%$ of the studies (Table 1). Declaration of financial competing interests by at least one investigator was associated with a significantly greater likelihood of favorable results for the drug or intervention under investigation $(\mathrm{p}<0.005)$. Similarly, sponsorship from industry was associated with more favorable results $(\mathrm{p}=0.03)$.Of the $8(7 \%)$ studies which were based on devices, only 2 had unfavorable outcomes. Six of those 8 studies reported conflict of interests. Rest of the 106 studies were based on drug intervention (drug vs placebo $=62$, drug vs standard treatment $=44$ ). The mean sample size of the trials included was $1,342 \pm 3,215$ with 25 (21.9\%) studies having a cohort of $>1,000$. Of these 25 studies, only one study had no competing interest.

\section{Discussion}

Our study shows that competing interests are extremely common among investigators of large phase 2 and phase 3 cardiovascular trials. Declaration of financial conflicts by at least one investigator is associated with a greater likelihood that results will favor the intervention studied. Competing interests among the investigators was deemed as a problem since more than 3 decades. ${ }^{2,3}$ Financial interests among the health care professionals related with US academia including those at the leadership positions suggest that the majority $(60 \%)$ of the chairpersons of the US institutions reported ties with the industry. ${ }^{4}$ Competing interests exist in both financial and nonfinancial forms, albeit the financial conflicts are the best recognized. The complex interplay of factors between the industry and physicians and how they can influence the research both consciously and unconsciously is difficult to establish. ${ }^{5}$ As suggested by Steinbrook et $\mathrm{al}^{6}{ }^{6}$ the key issue here is that not being influenced by the existing interests does not mean that the competing interests were not present.

Anderson et $\mathrm{al}^{7}$ showed that $41 \%$ of health care-related industries had at least one director linked with academic centers. Most of these were professionals from internal medicine and related specialties, especially cardiovascular medicine and oncology. Our study found that $22 \%$ of studies had investigators who had shares in the company. This creates a unique conflict. On one hand, the researcher is primarily interested in advancing science and ultimately benefiting the patients through the clinical trials. Possessing shares in the company is a financial incentive and the drug company is interested in generating revenues through the approval of the drug.

Several studies have shown that there is an association between the competing interests and the positive outcomes. ${ }^{8,9}$ It has also been shown that the medical students and trainees continue to receive gifts from the pharmaceutical companies despite institutional policies attempting to minimize such trends. ${ }^{10}$ These are often associated with promotional claims of the pharmaceutical companies that may be disproportionate to the actual efficacy and the adverse effects of the drug that is being marketed. However, despite this association, causality is difficult to prove. Moreover, there are instances where the interests of the patients, physicians, and industry can align. For instance, patients seek effective therapies, academia intends to translate the discoveries from the bench side to novel clinical strategies and the industry seeks such approaches to develop new products that can generate profit for them. ${ }^{11}$

Most of the studies in our analysis were sponsored by the industry, and such sponsorship has also been deemed to impact outcomes. ${ }^{1,5,12}$ Scientific integrity depends on ensuring patient safety and maintaining the highest ethical standards. The dynamics of physician and industry interactions are complex and devising mechanisms to foster scientific growth without hampering integrity are critical. Our results are limited by the small number of studies. Further research is needed to more closely examine the influence of different types of conflicts, including travel grants, lecture fees, research grants, honoraria and awards on the conduct of cardiovascular clinical trials.

\section{Disclosures}

The authors have no conflicts of interest to disclose.

1. Riaz H, Raza S, Khan MS, Riaz IB, Krasuski R. Impact of Funding Source on Clinical Trial Results Including Cardiovascular Outcome Trials. Am J Cardiol 2015;116:1944-1947.

2. Thompson DF. Understanding financial conflicts of interest. $N$ Engl J Med 1993;329:573-576.

3. Lentnek AL. Conflicts of interest. N Engl J Med 1994;330:503.

4. Campbell EG, Weissman JS, Ehringhaus S, Rao SR, Moy B, Feibelmann S, Goold SD. Institutional academic-industry relationships. JAMA 2007;298:1779-1786.

5. DeAngelis CD, Fontanarosa PB. Impugning the integrity of medical science: the adverse effects of industry influence. JAMA 2008;299: $1833-1835$

6. Steinbrook R, Kassirer JP, Angell M. Justifying conflicts of interest in medical journals: a very bad idea. BMJ 2015;350:2942.

7. Anderson TS, Good CB, Gellad WF. Prevalence and compensation of academic leaders, professors, and trustees on publicly traded US 
healthcarecompany boards of directors: cross sectional study. BMJ 2015;351:4826.

8. Wu Y, Deboeck P, Joseph M, Hwang C, Perlis CS, Perlis RH. Does study design explain the relationship between conflict of interest and positive outcome in clinical trials in psychiatry? J Clinpsychopharmacol 2009;29: 609-611.

9. Lopez J, Lopez S, Means J, Mohan R, Soni A, Milton J, Tufaro AP, May JW Jr, Dorafshar A. Financial conflicts of interest: an association between funding and findings in plastic surgery. Plast Reconstr Surg 2015;136:690-697.
10. Yeh JS, Austad KE, Franklin JM, Chimonas S, Campbell EG, Avorn J, Kesselheim AS. Association of medical students' reports of interactions with the pharmaceutical and medical device industries and medical school policies and characteristics: a cross-sectional study. Plos Med 2014;11:1001743.

11. Lo B. Serving two masters-conflicts of interest in academic medicine. N Engl J Med 2010;362:669-671.

12. Bekelman JE, Li Y, Gross CP. Scope and impact of financial conflicts of interest in biomedical research: a systematic review. JAMA 2003;289:454-465. 